\title{
JOINT ANGLE SENSORS FOR CLOSED-LOOP CONTROL
}

Wen H. Ko and Chih-Lei Miao

Electronics Design Center, Case Western Reserve University Cleveland, Ohio 44106

\section{ABSTRACT}

In order to substitute braces that have builtin goniometers and to provide feedback signals for closed-1oop control of lower-extremity Functional Neuromuscular System in paraplegics, a strechable capcitive sensor has been developed to accurately detect angular movement in joints. Promising clinical evaluations on the knee joints of a paraplegic and a volunteer have been done. The evaluations show great promise for the possibility of implantation applications.

\section{INTRODU CTION}

Research in Functional Electrical Stimulation is being undertaken utilizing a closed-1oop computer controlled 32 electrode stimulating system to enable paraplegics to walk normally as well as safely. Essential elements of this control system include sensors which measure the parameters to control and analyze movement of a walking subject. The sensor outputs and analyzed results will be used to activate the control function semiautomatically without the conscious aid of a human operator. One of the sensors needed in this system is a sensor to measure the joint angle. The present way to achieve this purpose is by using a mechanical brace with a built-in goniometer on each joint. The size, weight, accuracy and reliability of existing goniometers are not satisfactory. Problems include sliding of the device with movement, short lifetime, noise and poor cosmetic appearance. In addition, a goniometer can only operate with a bulky brace, requiring patients to wear the brace at al1 times. Therefore, it is desirable to develop an improved sensor for joint angle measurement, either for a surface mount or an implant inside the body. Human joints are complex structures and the pivot point of the angular motion shifts during a loop of the movement cycle. This makes conventional angular encoders unable to be used. After trying several designs the following approach has been adopted.

\section{DES IGN}

Figure $1 \mathrm{a}$ and $1 \mathrm{~b}$ illustrate the conceptual design and the operatating principle of the sensor. The design is paced on the fact that the change in capacitance is proportional to the angular displacement of the joint. The
3 mil wire wound

$1.125 \mathrm{~mm} \mathrm{O.D.}$ spring-loaded structure

silicone tubing

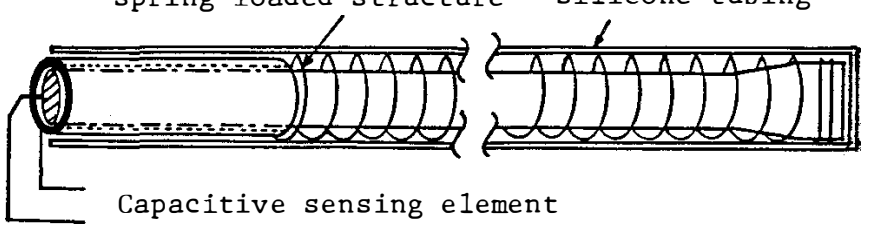

Figure 1a The Conceptual Design of the Joint Angle Sensor.

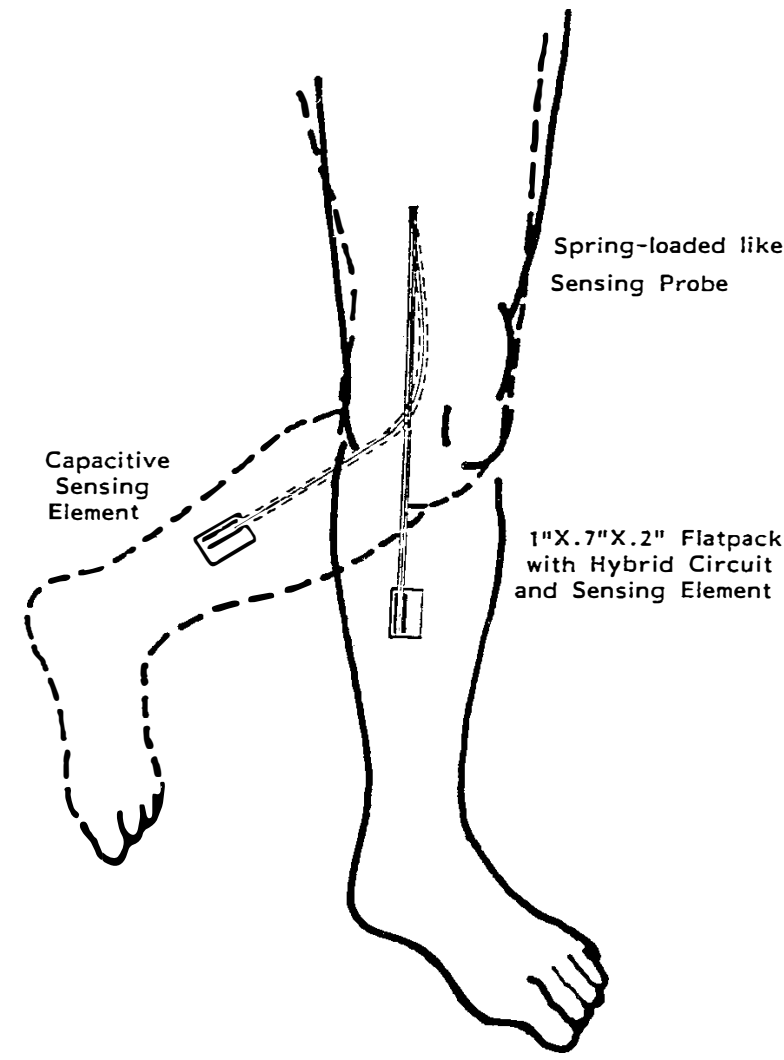

Figure $1 \mathrm{~b}$ The Operation Principle of the Joint Angle Sensor.

sensing element is encapsulated in medical grade silicone rubber tubing with an outer diameter of $1.125 \mathrm{~mm}$. The signal processing circuit incorporates CMOS hybrid circuitry packaged in a $1 " \times 0.7 " \times 0.2$ " metal flatback. [1] This circuit converts the capacitance changes of the sensing element into a DC output voltage. The circuit draws less than $1 \mathrm{~mA}$ using an 8 - 9 volt battery. A photograph of the prototype device is shown in Figure 2. 


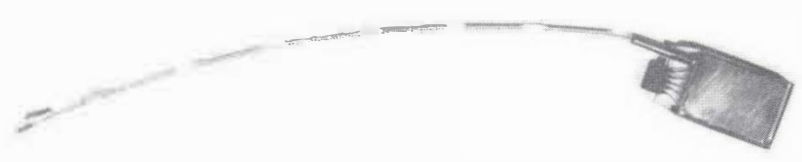

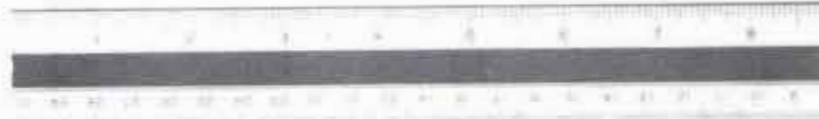

Figure 2 A Photograph of the Prototype Joint Angle Sensor.

\section{EXPERIMENTAL RESULTS}

The measured static characteristics of the sensor are listed in Table 1. The sensitivity of the sensor is $0.95 \mathrm{mV} / \mathrm{pf}$; the stability, over 72 hours, is $10 \mathrm{mV}$ drift at a 5 volt full output swing. Its temperature coefficient is 30 mv/ C. It has been tested throughout a temperature range of $4.5^{\circ} \mathrm{C}$ to $48.9^{\circ} \mathrm{C}\left(40^{\circ} \mathrm{F}\right.$ to $\left.120^{\circ} \mathrm{F}\right)$. Dynamic testing was performed by comparing this sensor, mounted near the knee, to a goniometer built in brace worn by the same person. The frequency reponse from $0 \mathrm{~Hz}$ up to more than $10 \mathrm{~Hz}$ is flat within $0.7 \mathrm{~dB}$. Comparison of the goniometer to the joint angle sensor and the frequency reponse data are illustrated in Figure $3 a$ and $3 b$.

Table 1 Specifications of the Joint Angle
Sensor PERFORMANCE

$\begin{array}{ll}\text { Total Range } & +0 \text { to }+180 \text { degrees } \\ \text { Linear Range } & +0 \text { to }+160 \text { degrees } \\ \text { Accuracy } & +22 \mathrm{mV} / \text { degree } \\ \text { Threshold and Resolution } & \pm 0.5 \text { degree } \\ \text { Linearity } & \pm 1 \text { percent angle } \\ \text { Repeatability } & \pm 0.5 \text { degree }\end{array}$

ELECTRICAL

$\begin{array}{ll}\text { Voltage Supply } & 8 \text { volts } \\ \text { Voltage Supple Range } & 6 \text { to } 15 \text { volts } \\ \text { Current Draw } & <1 \mathrm{~mA} \\ \text { Voltage Output } & 0.95 \mathrm{~V} / \mathrm{pf} \\ \text { Output Impedence } & 100 \mathrm{Kohm}\end{array}$

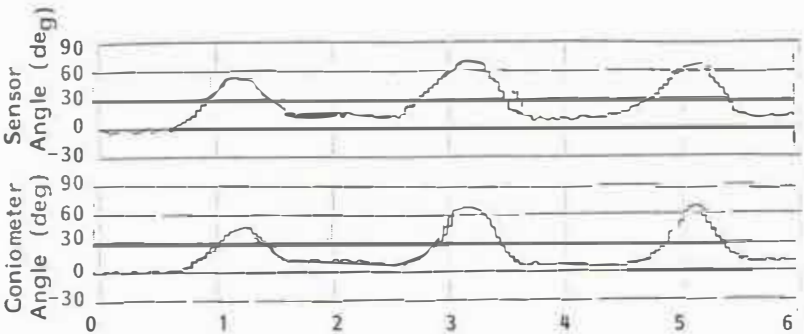

Figure 3a Comparision of the output of the Sensor to the Output of the Conimeter. ( $25 \mathrm{~Hz}$ Sampling rate)

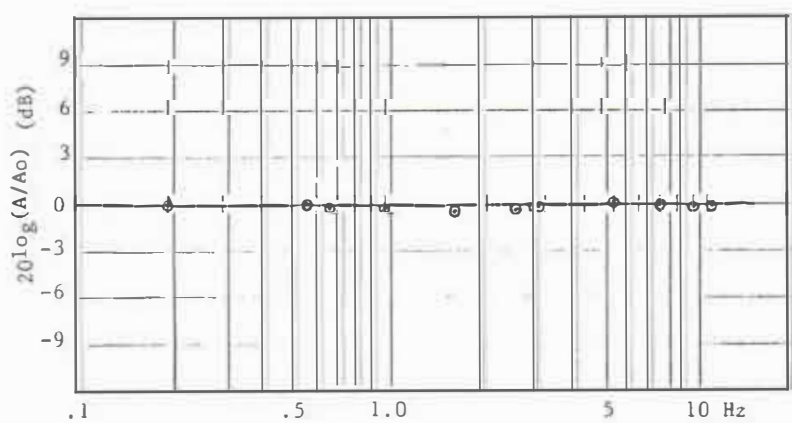

Figure 3b Frequency Response of the Joint Angle Sensor.

ENV IRONMENT

$\begin{array}{ll}\text { Temperature Range } & +40^{\circ} \mathrm{F} \text { to }+1200^{\circ} \mathrm{F} \\ \text { Tempreature Shift } & +1.4 \text { degree/ }{ }^{\circ} \mathrm{C}\end{array}$

RESULTS

If desired, the small temperature shift of the sensor can be compensated by electronic circuitry. The sensor appears to have good performance characteristics for both surface mounting and implant applications. Nevertheless, for widespread application, the capacitance measurement circuit will need to be integrated into a chip. Further studies are needec to eliminate calibration and mounting errors, as well as to design a biocompatible implant packages and procedures.

\section{REFERENCE}

1. G.J. Yeh, I. Dendo and W.H. Ko. "Switched Capcitor Interface Circuit for Capacitive Transducers", in Transducer, 185, International Conference on Solid-State Sensors and Actuators, June, 1985, pp. 60 63 . 